\title{
Innovation and Sustainable Development: The Question of Energy Efficiency
}

\author{
Iyad Dhaoui \\ Research Unit Money, Development and Infrastructures (MODEVI)/ Faculty of Economics and Management of \\ Sfax, Airport Road km 4.5, Sfax, 3018, Tunisia
}

\begin{abstract}
This article aims to examine the conditions in which technological innovation can foster and promote sustainable development. It takes into account all forms of technological innovation potential for sustainable development: process innovations, product innovations, organizational innovations, market innovations. It is also interested in the whole chain of innovation and pays particular attention to the plurality of devices innovation. This Research continues scientific representations which are guided by operational concerns.

This paper will attempt to discern the relationship between innovation and energy efficiency. Thus, we will describe the technology and process innovation for sustainable development and where energy consumption is minimized for a service rendered identical. We will put the findings into perspective in relation to the Tunisian context.
\end{abstract}

Keywords: Energy efficiency, Innovation, renewable energy, Tunisia.

\section{Introduction}

Faced with the ecological and social crisis that is manifested now in a global level (climate change, scarcity of natural resources, freshwater shortages, combination of peak oil, differences between developed and developing countries, food security, deforestation and drastic loss biodiversity, global population growth, natural and industrial disasters), sustainable development is a response to all stakeholders (governments, economic actors, civil society), cultural and social development.

\section{Conceptual Framework}

\section{II.1. Definition of sustainable development}

In 1972, the United Nations Conference on Environment adopted a set of principles for sound management of the environment. This statement has placed environmental issues in the international agenda and marked the beginning of a dialogue between industrialized and developing countries on the relationship between economic growth, pollution and the well-being of people all over the world

In 1987, the United Nations released the Brundtland Report, which included what is now one of the most widely recognized definitions: "Sustainable development is development that meets the needs of the present without compromising the ability of future generations to meet their own needs."

According to the same report, the above definition contains within it two key concepts:

- The concept of 'needs', in particular the essential needs of the world's poor, to which overriding priority should be given; and

- The idea of limitations imposed by the state of technology and social organization on the environment's ability to meet present and future needs.

This concept is not just about the environment. It is a goal that calls for policy changes in many sectors and requires coherence between policies. Everything lies in finding a balance between social, economic and environmental factors that constitute the three pillars of sustainable development. We must therefore take into account the impact of decisions taken at a given time on solutions that provide for future generations.

Sustainable development is a new conception of the public interest, applied to the economic growth and global reconsidered to take into account the environmental and social aspects of a globalized world. ${ }^{2}$

Sustainability requires the preservation, conservation of global capital over time.

The ethical argument is to consider that future generations have the right to inherit (in terms of human and natural capital overall) sufficient capital to enable them to have the measurements and the potential to generate and create a level well-being at least equivalent to that enjoyed by the present generation.

\footnotetext{
1 World Commission on Environment and Development."Our Common Future, Chapter 2: Towards Sustainable Development". Un-documents.net. Retrieved 2011-09-28.

${ }^{2}$ http://fr.wikipedia.org.wiki
} 
However, natural capital can suffer forms of degradation. To maintain this capital, a minimum of 3 rules can be set:

- The use of renewable resources should not exceed the rate of renewal level.

- Exhaustible resources must be extracted at a rate allowing their replacement by renewable resources.

- Emissions of all kinds of waste should be below the assimilative capacity of the environment.

\section{II.2. Sectors involved in sustainable development}

All sectors are concerned by sustainable development: agriculture, industry, housing, family organization; but also the services (finance, tourism, etc.) that, contrary to widespread opinion, are not only immaterial.

Figure 1. Scheme of sustainable development: at the confluence of three constituent parts.

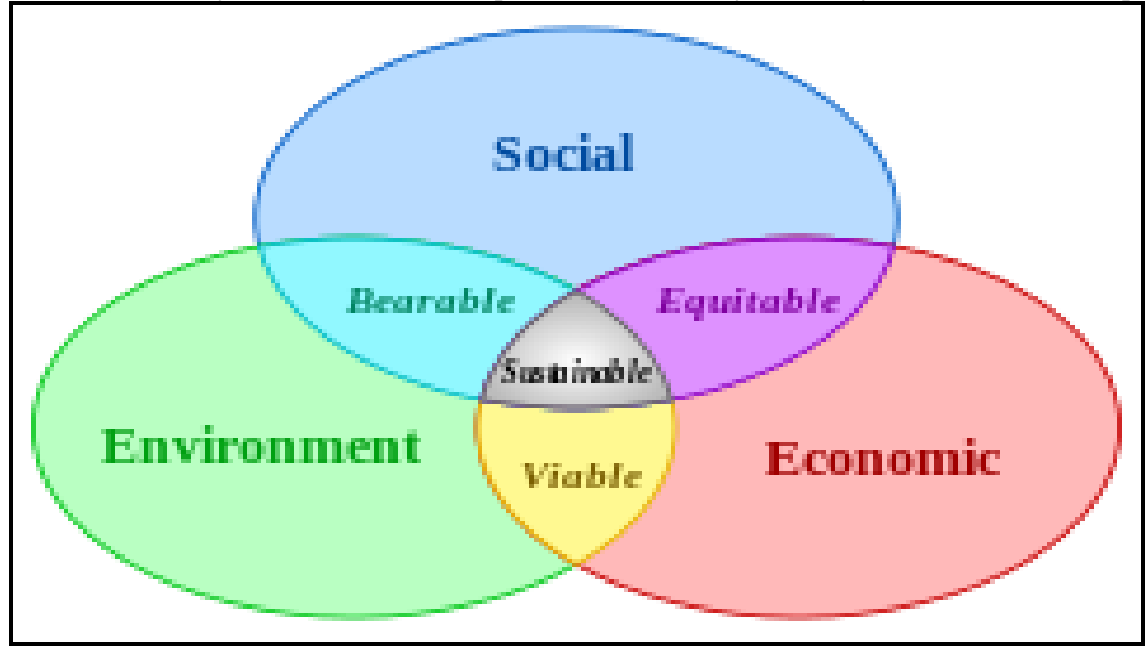

The above diagram describes a comprehensive approach to the confluence of three concerns, saying "the three pillars of sustainable development."

This reading can establish links between the different fields of education (citizenship, environment, global solidarity, and health) related to sustainable development, and thus make your project more comprehensive and citizen education.

\section{II.3. The three pillars of sustainable development}

The goal of sustainable development is to establish sustainable patterns that combine the economic, social, ecological and human activities: "three pillars" to take into account by companies as well as by individuals. The goal of sustainable development is to find a coherent balance and a long-term viable relationship between these three issues. These three pillars add a cross-cutting issue, essential to the definition and implementation of policies and actions relating to sustainable development governance. ${ }^{3}$

Governance involves the participation of all stakeholders (citizens, businesses, associations, elected, etc.) decision-making process. Thus, it is a form of participatory democracy. Sustainable development is not a static state of harmony, but rather a process of change in which the exploitation of resources, the direction of investments, the orientation of technological and institutional change are made consistent with future as with needs of the present ${ }^{4}$.

\section{II.4. Meet the needs of current and future generations}

Sustainable development is a development that meets the needs of the present without compromising the ability of future generations to meet their own needs. ${ }^{5}$

Preservation of the environment must be accompanied by the satisfaction of basic needs in terms of employment, food, energy, water, waste. However, we encounter a difficulty in defining what the needs of the

\footnotetext{
${ }^{3}$ The measurement of sustainable development according to the criteria of the Global Reporting Initiative incorporates governance indicators as well as the ecological, social and economic indicators.

${ }_{5}^{4}$ According to the Handbook of sustainable development criteria in the actions of international cooperation and solidarity.

${ }^{5}$ Brundtland Report.
} 
present, and what will be the needs of future generations. We could retain such basic needs for food, housing, and transportation.

In this context, sustainable development was included among the Millennium Development Goals by all Member States of the United Nations. ${ }^{6}$

To meet current needs without relying on unsustainable use of non-renewable resources, a scenario of three points was proposed:

- Effectiveness (more performant techniques);

- Sobriety (techniques used sparingly);

- Use of renewable resources (e.g., solar or wind through rural electrification projects).

\section{II.5. Innovation and Sustainable Development}

Technological innovation (designed to reduce waste and save the flow of materials and energy) and organizational innovation (industrial symbiosis of Kalundborg) are presented as viable in the short and long term (systematic utilization of waste, looping cycles, dematerialization of products.

Moreover, innovation plays an important role insofar as it reduces the costs of environmental degradation.



According to a study by the World Bank from 2009, the cost of environmental degradation would be $2.1 \%$ of GDP, both in terms of reducing production and loss of welfare caused by the deterioration of the quality of life.

Constraints on resources are becoming stronger. This phenomenon is likely to grow. The government has responded to this problem by increasing spending in the environmental protection, investment in infrastructure and enhancing its efforts in conservation. The main challenge is to put in place a clear policy framework and consistent for agriculture, industry, energy and tourism.

\section{Energy Efficiency}

All human activities, especially those that contribute to economic and social development, are related to energy. Indeed, the development of a society is reflected in the increasing satisfaction of certain needs: food, housing, health, education, leisure, etc. All these activities require energy consumption at varying degrees. The provision of energy is essential to economic and social development.

Indeed, the problem of depletion of fossil resources and the fight against global warming and energy independence will make renewable energy a political priority and a major challenge to sustainable development.

\section{III.1. The importance of using renewable energy sources in the context of sustainable development}

\section{$>$ Definition of renewable energy}

Renewable energy is a source of renewed energy quickly enough to be considered inexhaustible. The renewability of energy depends on the speed at which the source is regenerated, but the speed at which it is consumed. The behavior of energy consumers is a factor in the definition of renewable energy.

$>$ The main sources of renewable energy

- Solar energy:

${ }^{6}$ Sustainable Development: 7th Goal of the Millennium Development. 
Every hour, the sun sends to earth an amount of energy equivalent to 120000 terawatt/hours. This energy is free and available to the extent that technology allows the capture of an economical manner. Solar energy obviously generates a lot of heat, which is not partially captured and retained by the atmosphere, land and objects therein. To retain more energy that hits the surface of the earth, we need a technology for the capture, concentrate and, if necessary, transformed into electrical energy.

- Wind energy:

It is a renewable energy that does not emit any pollutant. Wind turbines can convert wind energy into more useful forms, such as electrical energy or mechanical energy to keep pumping water or air (RNC, website).

- Hydropower:

The use of hydropower has expanded dramatically throughout the world in the twentieth century. Today, it provides a significant portion of the world's electricity. Its principle is similar to that of wind power. Indeed, the mechanical energy of the water causes the wheel of a turbine, which in turn drives a generator. The latter converts the mechanical energy into electrical energy.

- Geothermal energy:

Geothermal heat pumps use the heat contained in the ground or water (groundwater or surface) and are based on different types of system (indirect or direct expansion, vertical or horizontal). Geothermal heat pumps recover heat from the ground via a coolant flowing through horizontal or vertical wells.

- Energy from Biomass:

Biomass energy includes the forms of renewable energy plant (that is to say the result of photosynthesis). These different forms of energy can come from wood, agricultural crops or other organic residues (animal or vegetable fats for example). There are different heating systems using biomass as fuel instead of oil or propane.

- Biofuels:

There are various types of biofuels, depending on the type of plant and the process of transformation from which they originate:

-Biodiesel: biofuels from oilseeds, made from vegetable oils obtained by pressing the seeds, or crude oil, soybeans or canola. Also, we found in this category methyl esters of vegetable oil, obtained by chemical transformation of these vegetable oils;

-Bioethanol: Biofuels produced from alcohol produced from plants containing sugar or starch;

-Biogas: biofuels produced by anaerobic fermentation of organic matter (animal fats, waste food waste, vegetable crops, etc.) which can then be used as fuel once purified.

- The methane (biogas):

Anaerobic digestion is a process of natural degradation of organic matter (fatty acids, fats, proteins, animal waste, etc.). By a microbiological flora in the absence of oxygen (anaerobic process), is to capture the methane gas (mainly methane) produced by the decomposition of the organic matter. This highly combustible gas can be used to produce heat or electricity or as fuel in vehicles.

\section{III.2. Definition of energy efficiency}

Energy efficiency is an operating condition of a system for which the energy consumption is minimized for a service rendered identical. This is a special case of the notion of efficiency and environmental performance element. Energy efficiency is a particular case of energy savings, which are designed to reduce energy consumption without necessarily the service is the same. In practice, it may be difficult to measure whether the service is or is not identical. Energy efficiency can reduce environmental costs, economic and social issues related to the production and consumption of energy. This is an important element of adaptation to climate change and the fight against greenhouse gas emissions.

\section{The Impact of The Use of Renewable Energy Sources on the Three Dimensions of Sustainable Development}

Renewable energy is able to develop energy through technologies developed by humans.

The provision of energy services to the poor is a challenge. The use of renewable energy can create energy supply so that it promotes the development, helps to reduce poverty, household environment and allows the creation of new jobs.

\section{IV.1. The contribution of renewable energy to the environmental dimension of sustainable development}

Because renewable energy sources result in less pollutant emissions than fossil fuels, the existing literature has limited environmental benefits of renewable energy to lower gas pollutants, in particular, greenhouse gas (GHG) emissions. 
This environmental benefit has grown, especially with the signing of the Kyoto Protocol by many countries, who see the use of renewable energy as an inevitable path to comply with their commitments in this protocol and therefore reduce the seriousness of climate change.

\section{IV.2. The contribution of renewable energy sources to the socio-economic dimension of sustainable}

The literature on renewable energy sources often lists their socio-economic benefits.

Chien and $\mathrm{Hu}$ (2007) analyze the effects of the use of renewable energy on technical efficiency of forty five economies between 2001 and 2002, using the model of Data Envelopment Analysis (DEA). In this model, labor, capital stock and consumption of energy are the three exogenous variables while the gross domestic product is the only endogenous variable Both analysis lead to the following result: increased use of renewable energy technology improves the efficiency of an economy, while increasing the use of traditional energy reduces technical efficiency. Goldemberg (2006) believes that renewable energy is a key to achieving sustainability. Indeed, the environmental problems at regional and global levels, as well as the dependence on energy imports and supply problems will persist if the global energy system will continue to be dominated by fossil fuels.

Turyareeba (2001) considers that the development of renewable energy will contribute to improving the living standards of the poor in rural areas. In addition, renewable energy can play a very important role in the modernization of agriculture is the main source of income and job creation in some countries.

\section{IV.3. The contribution of renewable energy to create jobs}

The literature that has focused on the impacts of the use of renewable energy on employment showed, generally, the existence of a positive effect. This has been verified by several studies in the context of European and American countries.

These studies show that renewable energy sources require more jobs than conventional energy for the same amount of energy produced.

However, it has a possibility of having negative effects on employment. Indeed, the negative impact on employment from the effect of contraction may outweigh the positive impacts associated with the expansionary effect, which brings us back to a net negative effect on employment in the long term.

\section{Development Policy of Renewable Energy in Tunisia}

\section{V.1. Renewable energy in Tunisia: strengths and limitations}

In the 70s and early 80s, thanks to the discovery of resources of oil and gas, energy has started playing a major role in the social and economic development in Tunisia. However, like the rest of the economy is developed and production has stagnated, the share of energy in GDP was reduced to only 5\% in 2004, compared to $13 \%$ in 1980.Energy is an important economic sector with export revenues reached 5.2 billion dinars in 2007, compared to 5.2 billion DT for textile and 0.7 billion DT for olive oil.

At the same time, royalties on oil production contribute significantly to government revenue but the balance between supply and demand is gradually tightened and the late 90 s, Tunisia became a net importer energy. Imports now cover a quarter of the energy needs.

Increasing dependence towards to imported hydrocarbons necessarily exposes domestic and / or state funds to the volatility of international energy markets.

\section{V.2. Constraints for the development of renewable energy in Tunisia}

Development of renewable energy in Tunisia faces certain constraints such as:

- Inadequate regulatory frameworks, despite progress in some areas to allow self-generation and give free access to the grid for the sale of electricity produced from renewable energy sources;

- The weakness of public funding and subsidies to conventional energy introduced by the State under the protection of poor social strata;

- Lack of local expertise;

- The limits of research and technology transfer.

To overcome these obstacles, the strategy of development of renewable energy developed by Tunisia is based on a comprehensive approach that takes into account the possibilities of industrial integration that creates added value and direct and indirect jobs, the development of research and skills. In addition, some current experiments show the importance and contribution of the Public-Private Partnership.

\section{VI.1. Milk production}

\section{Energy Efficiency in Agriculture}

\section{$>$ Refrigeration of milk with a plate heat exchanger}


Refrigeration of milk is responsible for about a quarter of the total electricity consumption on a dairy farm. Improved cooling efficiency could therefore provide significant cost savings.

To reduce the milk cooling load tank, pre-cooling systems have been designed, including plate heat exchanger. The plate heat exchanger can reduce the operating time of the compressor in the milk cooling and thus the amount of energy necessary for the preservation of milk.

A plate heat exchanger consists of a series of thin corrugated metal plates between which a number of channels are formed, with the primary and secondary fluids flowing through alternate channels. Heat transfer takes place from the primary fluid steam to the secondary process fluid in adjacent channels across the plate. Figure 3 shows a schematic representation of a plate heat exchanger.

Figure 3. Schematic diagram of a hear recovery system

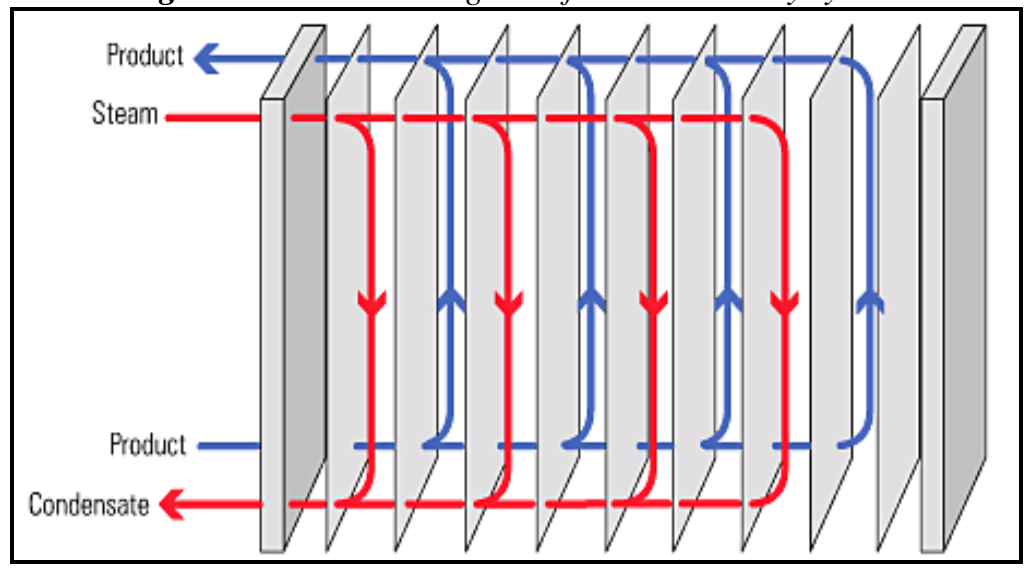

The exchange of cold / heat lowers decrease the temperature of the milk from $36^{\circ} \mathrm{C}$ to $16-23^{\circ} \mathrm{C}$ for an average difference of $16^{\circ} \mathrm{C}$. After passing through the plate heat exchanger, the milk is stored in the milk tank to be then cooled to the storage temperature (around $3^{\circ} \mathrm{C}$ ).

\section{$>$ Recovering heat for heating water}

Heating water consumes a significant part of the energy on the farm. The water is heated with electricity or propane. Whatever the source of energy used, the inlet temperature of the water in the water heater has a major impact on the cost of heating water.

The installation of a heat recovery system can use a free and available heat source. This system allows reusing the heat generated by the process of cooling of the milk.

Figure 4. Schematic diagram of a hear recovery system

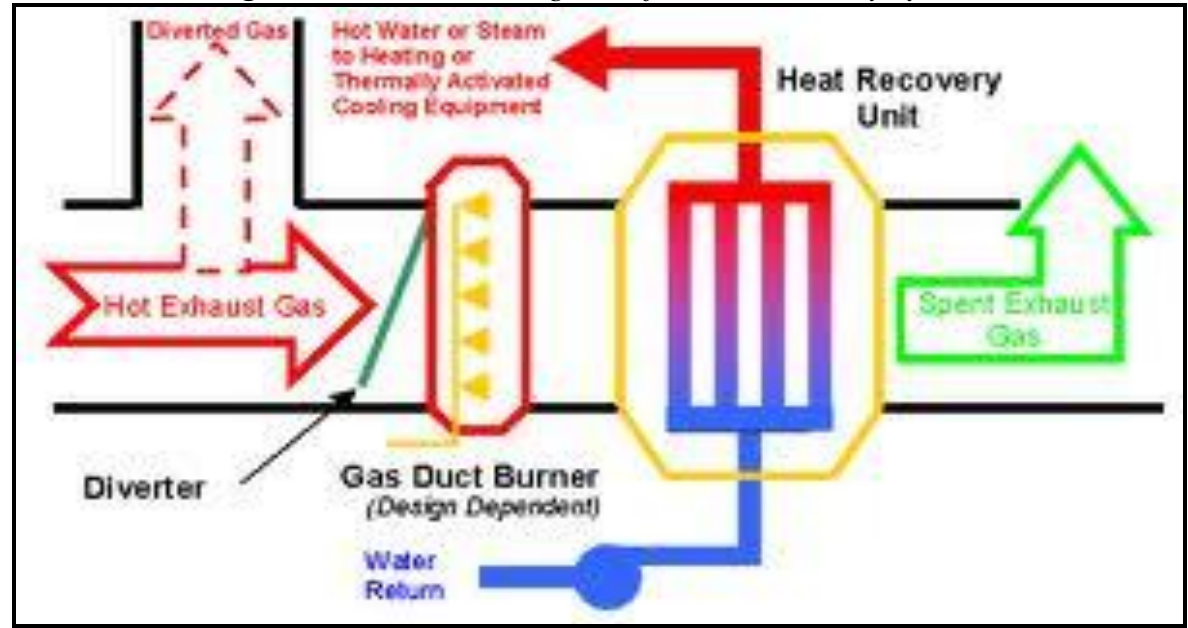

The milk is cooled by a refrigeration system which transfers the heat from a source (milk) to a sink (water or air) through a refrigerant gas. The heat of the refrigerant gas is then usually lost in the atmosphere of the dairy or outside the building. The heat recovery system does not fundamentally change the operation of the refrigeration system but allow reuse of heat usually lost.

\section{VI.2. Efficient lighting}

Given the importance of spending lighting on a dairy farm, it is necessary to look at some technologies that reduce these costs while guaranteeing to maintain the productivity of cows. Indeed, research 
shows that a light of 108 to 250 lux for a period of 16 to 18 hours followed by a period of darkness of 6 to 8 hours results in increased milk production of 5 to $16 \%$. Thus, it seems appropriate to "better light".

Technologies with the greatest potential are metal halide lamps and fluorescent lamps. They have a life far superior to commonly used incandescent lamps (10,000 to 20,000 hours against 750 to 2000 hours). Incandescent lamps are less efficient than fluorescent lamps (15 to 20 lumen / Watt against 50 to 80).

Figure 5. The fluorescent lamps



When replacing incandescent lamps with mercury lamps or fluorescent lamps, the producer must keep in mind the importance of calibrating installation versus "needs" of his herd. The type of efficient lighting may depend on the height of buildings and its configuration (free or hindered stall, height and shape of the roof), other parameters such as the cleaning of buildings, etc. ${ }^{7}$

\section{VI.3. Production of table eggs and hatching}

Production of table eggs and hatching, as poultry production in general, are little energy intensive sectors. The production of hatching eggs requires more energy because the stocking density is lower and the heating needs of buildings so superior.

One way to reduce energy costs for heating is to use a solar wall.

The solar wall uses the energy of sunlight to preheat the incoming air in buildings. The solar collector comprises a double sheet wall aluminum or steel) of black color, the surface of which is perforated top heated by solar radiation. The energy captured by the solar wall is sunlight, not heat. Thus, it can generate as much energy in winter than in summer.

Figure 6. The solar wall pattern

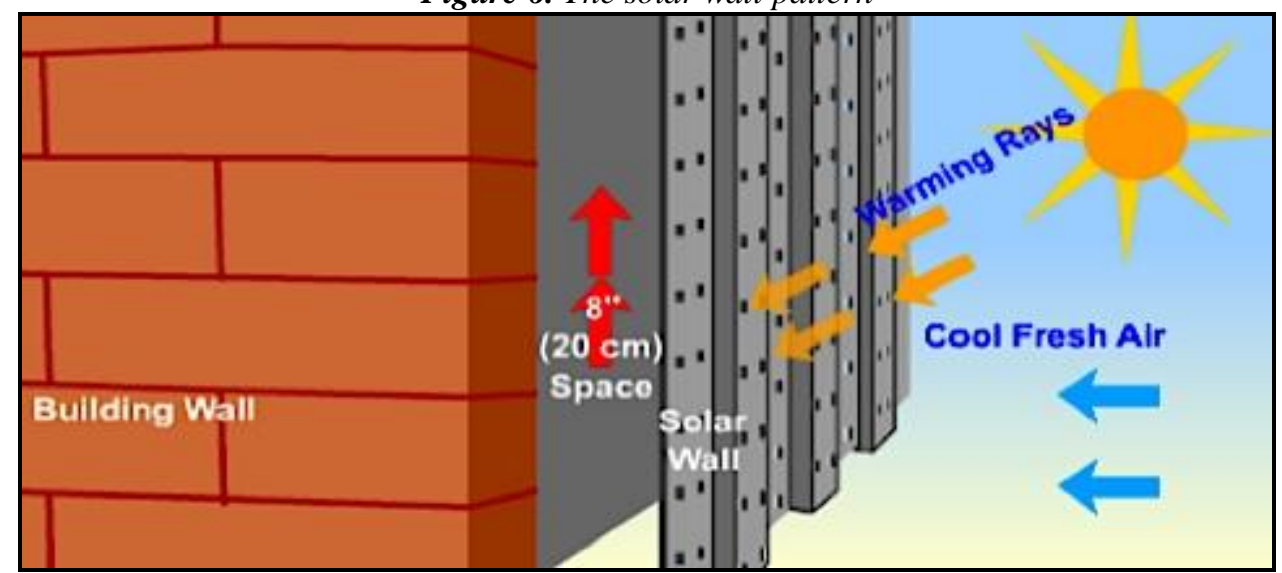

Thus, this technology offers the potential for greater energy savings in colder climates because the difference between the outdoor temperature and the desired temperature inside the building is higher. The solar wall can also be used with a natural ventilation system.

\section{$>$ ventilation}

\footnotetext{
${ }^{7}$ Fortier M. and al, (2005), «L'éclairage des étables laitières » MAPAQ, p.9.
} 
Ventilation is a crucial function in the poultry business because it helps maintain good air quality essential to the health of animals. According to the experts, there would be no major technological innovations to significantly reduce the energy consumption of this type of device.

The only issues raised is the need to properly adapt the dimensions of the fan to the size of buildings and needs air flow and get the fans with the best characteristics in terms of energy efficiency when renewing these .

\section{$>$ Refrigeration of eggs}

Refrigeration of eggs needs relatively minor power consumption in the poultry companies. As in the case of ventilation, there are no new technologies which present current interest in the sector to reduce energy costs for refrigeration eggs.

Cooling loads and temperatures instructions refrigerators in the poultry production does not justify the installation of heat recovery system.

\section{Energy Efficiency in Industry: Existing Technologies for Innovative Solutions}

Faced to the inevitable tensions on oil and fossil fuels, with a gradual depletion of fossil resources and constraints on $\mathrm{CO} 2$ emissions which can only strengthen, the major manufacturers as well as SMEs should continue efforts to energy efficiency.

The potential for energy efficiency and reducing $\mathrm{CO} 2$ emissions, is built through better energy management, implementation of new uses with a high performance, using energy with low carbon content, re-process designs, and the recovery and enhancement of heat lost today.

\section{VII.1. Deposits energy savings by sector of activity}

The main sources of economy today are identified on the one hand the management of utilities, that is to say, steam, cold, compressed air or environmental conditioning of the premises, and secondly on the centralized technical management of the energy, that is to say the overall optimization of the energy consumption. ${ }^{8}$ Industrial processes themselves contain deposits of very high energy efficiency often poorly estimated. Unit gains range from 20 to $90 \%$ (significant gains in the example of the use of membranes or drying performance). The choice of technology in an investment will be dictated by technical and economic factors, including energy efficiency, but after the quality, productivity and flexibility. The use of performant electrical techniques ${ }^{9}$ often leads to a higher investment cost but contributes not only to improved energy efficiency, but also more compact, precision, reliability and speed of the process where better quality control and increased productivity. The techno-economic analysis of the potential savings in energy industry reveals, the complexity and diversity of industrial processes, the main technical targets of energy efficiency: heat production (boilers, $34 \%$ of consumption and $14 \%$ of deposits), uses heat (ovens and drying, $28 \%$ cons. deposits and $31 \%$ ), and environmental conditioning of premises (only $8 \%$ of consumption but $13 \%$ of deposits). Fatal heat recovery with conventional technologies on boilers and cold already represents $26 \%$ of deposits. ${ }^{10}$

\section{VII.2. Heating technologies with high energy performance}

Induction is the best available technology for heating solid food processing industries and metallurgy (heat treatment of metals and fusion). Accurate and efficient, induction is used either for direct heating of metals, for the heating of fluids in a vessel with the following benefits:

- Heat is generated within the material to be heated, hence minimizing drastic energy losses due to transfers;

- The thermal inertia is very low and high power density (up to $4 \mathrm{MW} / \mathrm{m} 2$ )

- The power modulation, the reproducibility of treatment cycles and automation are easy and provide great flexibility;

- The loss of material on the product by oxidation are reduced, productivity gains.

Importantly, induction heating has a high energy efficiency compared to flame heating or steam. It can be divided by two in final energy consumption.

Use "Stop and Go" (no preheating or standby) can also obtain substantial energy savings. ${ }^{11}$

Depending on the application, the induction heating competes with heating flame (oxy-fuel furnaces or gas) or resistance heating. Penetration in the industry as induction heating mode performance is only in its infancy, even

\footnotetext{
8 IEA report, 2007, "Tracking Industrial Energy Efficiency and CO2 Emissions".

9 Bamberger Y, "Davantage d'électricité pour moins de CO2", Réalités Industrielles, Nov 2008.

10 Terrien P., 2008, "ECLEER and Energy Efficiency in Industry", Electricité de France Workshop Printemps de la Recherche, Les Renardières, June.

${ }^{11}$ Baake E., "Energy efficient use of electricity in metallurgical processes", XVI int. congress on Electricity applications in a modern world, UIE'08 Krakow (Poland), May 19-21, 2008.
} 
if it is already established foundry in the early transformations of steel mechanical, automobile production, and more marginally parachemistry and food processing industries.

This electro-thermal technique still has significant potential for technological progress. Thus the concept of "universal inducer" development couples generators / drivers for greater adaptability to the load equipment, makes much more generic, less expensive and suitable for new applications. This technological breakthrough could enter the market between 2010 and 2015, and eventually double the market of induction.

\section{VII.3. Recuperative and amplifying technologies}

As indicated above, the valuation of fatal heat represents efficiency huge deposits, subject to the availability of appropriate technologies. ${ }^{12}$

Three recovery fatal heat technologies must be improved:

- Heat exchangers, for example by investigating the micro-channel heat exchangers;

- Techno. Thermo. : Heat Pump Cover (HPC), mechanical vapor compression (MCV);

- Organic Rankine cycle-or low pressure steam.

\section{VII.4. In conclusion, three major research areas should be investigated}

Developments in numerical methods and tools that can contribute to the optimization of industrial manufacturing lines, with up to consider their re-design to target high energy integration and extending these analyzes to industries never investigated by the methods: analysis of energy flow, re-design process taking into account the life cycle analysis, economic factors, monitoring and control, the development of energy-efficient technologies with energy integration for each ad hoc industrial processes such as induction heating furnaces ultra rapid integration of renewable energy in their processes and storage, measuring chains at low cost, research on the valuation of any calories lost in the industry, developing technologies and recuperative enhancer: HPC industrial MCV, innovative interchanges.

\section{Conclusion}

Make technological innovation for sustainable development is a complex challenge, because the concepts of innovation and sustainable development are both multidimensional. Also, characterize the technologies for sustainable development should not focus only on the technology itself, but also on the process of design and delivery. The key to sustainable development lies in the following three dimensions: technology, organizational innovation, changes in lifestyles. Farmers, industry and consumers will change their habits if they want to improve their well-being, without suffering from environmental degradation.

Tunisia has the necessary assets to join the era of the knowledge society, provided that all components of society understand that the most important resource we have and who is able to help us meet the many challenges of the future, including our contemporary world, complex and hard in many ways, is precisely our human resource, to which Tunisia has focused since its independence. However, there remains much work to be done. This requires in particular a great effort to generalize the culture of research and encouragement of excellence. Put technological innovation for sustainable development is a complex challenge, because the concepts of innovation and sustainable development are both multidimensional. Also characterize the technologies for sustainable development, knowing that the characterization should not focus only on the technology itself, but also on the process of design and delivery. The key to sustainable development lies in the following three: technology, organizational innovation, changes in lifestyles.

Through various analyzes, we discerned that the energy efficiency for Tunisia is a key issue. Thus, the use of renewable energy is imperative. Technological innovation plays a vital role in so far as it is favorable to sustainable development, taking into account not only environmental, but also other dimensions of sustainable development.

\section{References}

[1] Blundell, R. and al. (1999), Market share, market value and innovation in a panel of British manufacturing firms, Review of Economic Studies, vol. 66, N³, pp.529-554.

[2] Le Bas, C. (2008), L'innovation dans la théorie économique, LEFI, Université Lyon 2.

[3] Frank, F. (1998), Recherche, invention et innovation, Ed Economica.

[4] Chien, T. et Hu, J.L. (2007), Renewable energy and macroeconomic efficiency of OECD and non OECD economics, Energy Policy, Vol.35, pp: 3606-3615.

[5] Aghion, P. and Griffith, R. (2005), Competition and growth: reconciling theory and evidence, Cambridge, MA, MIT Press.

\footnotetext{
12 Palandre L., Clodic D., 2007, “Alternative thermodynamic Cycles for a high efficiency heat pump dryer”, IIF-IIR Int Refrigeration congress, Beijing.
} 
[6] Arnaud, D. (2011), La technologie au cour du développement durable : mythe ou réalité ?, Université Blaise Pascal, CERDI Clermont-Ferrand ; TRIANGLE, Lyon

[7] Baden-Fuller, C. and Pitt, M. (1996), Strategic innovation, Routledge, Londres.

[8] Bamberger, Y. (2008), Davantage d'électricité pour moins de CO2, Réalités Industrielles.

[9] Barnu, F. (2010), La vraie nature de l'innovation, pourquoi elle remet en cause les fondements de l'entreprise, Edition Tec et Doc.

[10] Bellon, B. (2002), L'innovation créatrice, Economica, Paris.

[11] Turyareeba, P.J. (2001), Renewable energy: its contribution to improved standards of living and modernization of agriculture in Uganda, Renewable Energy, Vol.24, pp: 453-457.

[12] Enos, J- L. (1962), Invention and innovation in the petroleum refining industry, In the rate and direction of inventive activity: Economic and social factors, Princeton University Press, Princeton.

[13] Fortier, M. et al. (2005), L'éclairage des étables laitières, MAPAQ.

[14] Goldenberg, J. (2006), The promise of clean energy, Energy Policy, Vol.34, pp: 2185-2190.

[15] Gongi, N. (2010), Les mécanismes et structure de soutien de l'innovation en Tunisie, MFCPOLE.

[16] Guellec, D. (1999), Economie de l'Innovation, Les fiches de lecture de la Chaire D.S.O, La Découverte.

[17] Kline, J. and Rosenberg, N. (1986), An Overview of Innovation, in R. Landau and N. Rosenberg (eds), The Positive Sum Strategies: harnessing Technology for Economic Growth, Washington DC, National Academic Press, pp: 275-305.

[18] Le Bas, C. (1999), Economie de l'innovation, Collection Economie, Paris.

[19] Schumpeter, J. (1939), Business Cycle: A Theoretical, Historical and Statistical Analysis of the Capitalist Process, New York Toronto London: McGraw-Hill Book Company.

[20] Lester, R. K. and Piore M- J. (2004), Innovation: The Missing dimension, Cambridge (Mass.), Harvard University Press.

[21] Levacher, L. et al. (2000), Efficacité énergétique pour l'industrie : des technologies existantes aux solutions innovantes, European Center Laboratories for Energy Efiiciency Research.

[22] Linnhoff, M. (1998), Introduction to pinch technology, Targeting House, Gadbrook Park, Northwich, Cheshire, CW9 7UZ, England.

[23] Abou-Khalil, B. and al. (2008), A method for energy optimization of industrial product transformation in Small and Medium-Size Enterprises, PRES 2008, Praha, Czech Rep., 2008.

[24] Terrien, P. (2008), ECLEER and Energy Efficiency in Industry, Electricité de France Workshop Printemps de la Recherche, Les Renardières, June.

[25] Malthus, T. R. (1798), Principes d'économie politique, Édition Colman-Lévy, Nov. 1969.

[26] Miéville, L. (2008), Elements of innovation, Unitec, UniGe-HUG, Université de Genève.

[27] Moldaschl, M. (2010), Why Innovation Theories Make no Sense, Papers and Preprints of the Department of Innovation Research and Sustainable Resource Management (BWL IX), Chemnitz University of Technology, No. 9.

[28] Moumen, M. (2003), Utilisation rationnelle des eaux d'irrigation : reconversion de l'aspersion en localisée dans le Lukkos, Revue H.T.E, $\mathrm{N}^{\circ} 125$.

[29] Nelson, R- R. and Winter, S-G. (1982), An Evolutionary Theory of Economic Change. Belknap Press/Harvard University Press: Cambridge.

[30] Ricardo, D. (1817), Principes de l'économie politique et de l'impôt, trad. française, 1847.

[31] Schmookler, J. (1966), Invention and economic growth. Cambridge, Mass., Harvard University Press

[32] Patris, C. et al. (2001), L’innovation technologique au service du développement durable, Centre de recherche Travail \& Technologies, Fondation Travail-Université (Namur).

[33] Sismondi, J-.C. (1819), Nouveaux principes d'économie politique, Delaunay, Libraire, Paris.

[34] Pistorius, W-I. and Utterback, J-M. (1997), Multi-mode interaction among technologies, Research Policy, $\mathrm{N}^{\circ} 26, \mathrm{pp}: 67-84$.

[35] Porter, M-E (1998), Clusters and the New Economics of Competition, Harvard Business Review.

[36] Schumpeter, J. (1912), The theory of economic development: An inquiry into profits, capital, credit, interest, and the business cycle, MA: Harvard University Press.

[37] Smith A. (1776), Recherches sur la nature et les causes de la richesse des nations, Édition Gallimard.

[38] Paya, B. (2008), Investigation on energy recovering in an induction coil for continuous through heating billet, Przeglad Elektrotechniczny (Elec. Rev.), ISSN0033-2097, R.84 NR11/2008, p.129-133.

[39] Mansfield, E. (1983), Technological change and MA: an empirical study, The American Economic Review, Vol. 73, N², pp: 205209.

[40] Marx, K. (1919), Le Capital, Édition populaire (résumés-extraits), Édition populaire (résumés-Extraits) Par Julien Borchardt Texte français établi par J.-P. Samson.

[41] Solow, R. (1957), Technical change and the aggregate production function, Review of Economics and Statistics, Vol. 39, N³, pp 312-320.

[42] Chouteau, M. et Viévard, L. (2007), L'innovation : un processus à décrypter, Le centre Ressources Prospective du Grand Lyon. 